\title{
Biologic agents in immune-mediated inflammatory rheumatic diseases: current state of the art and clinical practice in Romania
}

\author{
Bălănescu A., Bălănescu D., Donisan T. \\ University of Medicine and Pharmacy «Carol Davila», Bucharest, Romania \\ Strada Dionisie Lupu, nr. 37, Sector 2, Bucharest, Romania
}

The article describes a wide spectrum of biological agents for treatment of Immune-mediated inflammatory rheumatic diseases in clinical practice in EU. Pharmacological classification, main characteristics of anti-TNF agents and biologics with another modes of action, as well as the most important results of clinical trials are provided. Authors focused on the use of biological agents in clinical practice in emerging market regions such as Central and Eastern Europe, particularly in Romania, were disparity due to economic and social factors provides challenges to achieving optimal monitoring and physician's decision making. Such very important points as an adoption of «treat to target» recommendations to local practice, consensus guidelines on the criteria for biological treatment, patient education initiatives, the development of a national patients registry, are discussed.

Key words: rheumatic diseases; biologic agents; clinical practice; treat totarget; emerging markets.

Contact: Dinu Bălănescu; dinu.balanescu@yahoo.com

For reference: Bălănescu A, Bălănescu D, Donisan T. Biologic agents in immune-mediated inflammatory rheumatic diseases: current state of the art and clinical practice in Romania. Sovremennaya Revmatologiya=Modern Rheumatology Journal. 2017;11(3):91-98.

DOI: http://dx.doi.org/10/14412/1996-7012-2017-3-91-98

\section{General principles}

Immune-mediated inflammatory rheumatic diseases are clinical entities with unknown etiologies, partially discovered pathogenesis, and complex presentation. Great progress has been made in the last few years in the understanding of the immunological mechanisms underlying the pathogenic processes of these diseases. Together with the development of biologic and genetic engineering techniques, these have led to the appearance of new, highly effective therapeutic agents that have revolutionized the treatment of such diseases.

Biologic agents are therapeutic tools produced by human genes that are introduced in cellular cultures of various origins, using genetic engineering. This results in artificial products that copy the biologic effects of natural substances. They are fundamentally different from usual drugs, not only because of the way they are obtained (the latter originating from usual chemical processes), but also because of their mechanism of action. Biologic agents have a strictly specific effect, directed against a unique target (a molecule or a cellular receptor) [1].

Biologic agents can be grouped in several categories:

- Monoclonal antibodies (Ab), recognized by the êmab suffix (from ímonoclonal antibodiesì), are $\mathrm{Ab}$ with high specificity and affinity, produced by a single lymphocytic clone, coming from a single stem cell. Monoclonal Ab can be:

- Chimeric - an Ab made by fusing the antigen-binding region (variable domains of the heavy and light chains) from a mouse, with a human constant domain (effector region). The murinic part represents about $25 \%$ of the molecule.äThe chimeric antibodies retain the original antibodyïs antigen specificity and affinity. They are recognized by the êimab suffix.

- Humanized ê in which the Fab fragment is replaced with a human fragment, leaving just the paratope of murinic origin, which represents about $10 \%$ of the entire molecule (recognized by the êzumab suffix).
- Human ê completely made up from human components (recognized by the êmumab suffix).

- Receptor antagonists are products with the capacity to bind to cellular receptors, but generating no biologic response. Thus, the receptor antagonists have affinity, but no efficacy, being biologically inactive. They compete with the endogenous agonist of the membrane receptor.

- Soluble receptors (recognized by the êcept suffix) are fragments of the extramembrane or intracytoplasmic portion of the membrane receptor. They have a high affinity for the receptorïs agonist and bind to it before it can reach the target cell. This prevents the agonist from reaching the cell and binding to its receptor, thus preventing the effects of the cellular activation.

Another classification of the biologic agents used in rheumatology sorts them by molecular target:

- Anticytokine agents:

- Anti-tumor necrosis factor- $\alpha$ (TNF- $\alpha$ ): monoclonal $\mathrm{Ab}$ against TNF- $\alpha$ (Infliximab, Adalimumab, Golimumab, Certolizumab) and soluble TNF- $\alpha$ receptor (Etanercept)

- Anti-interleukin 6 (IL-6): monoclonal Ab against IL-6 (Tocilizumab)

- Anti-interleukin 1 (IL-1): monoclonal Ab against IL-1 (Anakinra)

- Anti-interleukin 17 (IL-17): completely humanized monoclonal Ab against IL-17A (Sekukinumab)

- Anti-interleukins 12/23 (IL-12, IL-23): humanized monoclonal $\mathrm{Ab}$ against the $\mathrm{p} 40$ subunit of IL-12 and IL-23 (Ustekinumab)

- Noncytokine agents:

- Anti-B lymphocyte agents:

- Monoclonal Ab against CD20, receptor found on the surface of B lymphocytes (Rituximab) 


\section{О БЗ 30 Р Ы}

\author{
- Monoclonal Ab against BLyS (B-lymphocyte stimulator) ê \\ (Belimumab)
}

\section{Anti-cytokine agents}

\subsection{Anti-TNF- $\alpha$ agents}

TNF- $\alpha$ is one of the most important proinflammatory cytokines, whose role in the pathogenesis of rheumatoid arthritis (RA), ankylosing spondylitis (AS) and psoriatic arthritis (PsA) is extremely important. This cytokine is responsible for many pathogenic processes, such as: presenting antigens, facilitating the immune response, stimulating $\mathrm{T}$ lymphocytes, cellular infiltration, initiating and maintaining inflammation, osteoclast activation and bone resorption, matrix-metalloproteinase synthesis and articular cartilage degradation, and vascular proliferation (angiogenesis) [2-4].

This cytokine also has many physiological purposes, the most important of which being its anti-tumoral and anti-mycobacterial effects. TNF- $\alpha$ has a major role in forming and maintaining the mycobacterial granuloma, so therapies with TNF- $\alpha$ blockers could predispose to new tuberculosis (TB) infections, or latent TB activation. This imposes the necessity of thorough TB screening before starting patients on anti-TNF- $\alpha$ agents.

The activity of TNF- $\alpha$ can be blocked either with the use of monoclonal $\mathrm{Ab}$ targeted against this cytokine, or through soluble TNF- $\alpha$ receptors. The cytokine is neutralized in both situations, not being able to reach its cellular target, and the inflammatory stimulus is blocked.

Infliximab is a type $\operatorname{IgG} 1$ chimeric monoclonal $\mathrm{Ab}$, binding to TNF- $\alpha$ and blocking its activity.

The usual dosage is $3-10 \mathrm{mg} / \mathrm{kg}$ (in AS it is greater than in RA, varying between $5-10 \mathrm{mg} / \mathrm{kg}$ ), administered in IV infusions at weeks $0,2,6$, and then every 8 weeks. If the response is insufficient or lost, the dose can be slowly increased to the maximum allowed one, or the administration interval can be decreased to 6 weeks.

In RA, the ATTRACT study (Anti-Tumor Necrosis Factor Trial in Rheumatoid Arthritis with Concomitant Therapy) proved that when given in combination with Methotrexate (MTX), Infliximab is more efficient than MTX monotherapy in reducing clinical signs and symptoms, improving physical function and quality of life, and inhibiting the progression of structural damage $[5,6]$. These results have been confirmed by a wide number of studies which have proven the long term results of Infliximab [6-8].

In AS, Infliximab was evaluated in the ASSERT study, showing very good clinical results: $61.2 \%$ of the patients had an ASAS20\% response at 24 weeks, and vertebral inflammation evaluated using MRI was significantly diminished $[9,10]$. Numerous other studies have afterwards underlined the efficacy of using Infliximab in AS, not only clinically, but also by the reduction of inflammation visualized using MRI and also functionally, the effects being sustained, over periods exceeding 8 years [11]. Furthermore, Infliximab has been proven to be efficient also in non-radiographic AS, as shown on a subgroup of the patients in the INFAST study [12].

Infliximab has shown its use in PsA in various clinical studies, like IMPACT II. This trial found that $58 \%$ of the patients treated with Infliximab had an ACR20 response at 14 weeks, and that dactylitis and enthesitis were improved [13]. Furthermore, after 24 weeks, the cutaneous manifestations were much improved, 64\% of the patients reaching a PASI75 response. Patients treated with Infliximab also experienced inhibition of the radiographic progression after 24 weeks, as well as functional and quality of life improvements. The extension of the study to 2 years proved the sustained therapeutic effect of Infliximab.
Adalimumab is a completely humanized anti-TNF- $\alpha$ monoclonal $\mathrm{Ab}$. The dose is $40 \mathrm{mg}$ every 2 weeks, administered subcutaneously.

The ARMADA study proved the favorable effects of combining MTX and Adalimumab on all the clinical and radiologic parameters followed in RA patients [14]. Other studies have looked into the benefic effects and the safety of the treatment with Adalimumab combined with MTX or another disease-modifying agent or as monotherapy, not only from a clinical point of view, but also from a radiologic one, at 24 weeks or on the long term, in the early and late phases of RA [15-18].

Adalimumab has been intensely studied in AS. The ATLAS study showed that $58.2 \%$ of the patients treated with Adalimumab reached an ASAS20\% response after 12 weeks [19]. Furthermore, there are data (from a subgroup of patients enrolled in ATLAS, but also from other studies) which shows that Adalimumab has favorable clinical results in patients with advanced disease, even with spinal ankylosis [20]. The Adalimumab dose used in AS is similar to the one from RA, $40 \mathrm{mg}$ subcutaneously every 2 weeks. In the ABILITY-1 study, Adalimumab was efficient even in patients with non-radiographic spondyloarthritis, thus being recommended for this clinical entity as well [21].

Golimumab is a human anti-TNF- $\alpha$ monoclonal $\mathrm{Ab}$, administered subcutaneously, $50 \mathrm{mg}$ once per month.

In RA, Golimumab was studied in a complex research program, which included patients who had not been treated with disease-modifying antirheumatic drugs (DMARDs), patients who had had no response to MTX and patients for whom another TNF- $\alpha$ blocker had failed. All these studies showed that Golimumab was able of improving symptoms and physical function and halting structural lesions in patients with RA, not only on the short term, but on the long term as well $[22,23]$.

Golimumab was evaluated in AS in the GO-RAISE study, in which $60 \%$ of the patients obtained an ASAS20 response after 14 weeks, and a significant improvement in BASDAI and BASFI scores, as well in their quality of life after 6 months [24].

In PsA, Golimumab showed articular and cutaneous clinical improvements, with the slowdown of radiologic progression, as proven in the GO-REVEAL study and its 2 and 5 years extensions $[25,26]$.

Certolizumab is a human anti-TNF- $\alpha$ monoclonal Ab. It is composed only from the Fab fragment of the Ig and it is pegylated (coated with polyethylene glycol). When the treatment is initiated, 2 subcutaneous injections are administered (400 $\mathrm{mg}$ ) in weeks 0,2 and 4, and then the maintenance dose is 1 subcutaneous injection $(200 \mathrm{mg})$ every 2 weeks. Pegylation grants Certolizumab a few biological properties: because of the higher molecular weight, the half-time is increased, it diffuses less in normal tissues and more in regions of inflammation, mast cell degranulation is inhibited, decreasing injection-site reactions, and the molecule does not cross the placenta, making this drug suitable for use in pregnant women [27].

The RAPID I and RAPID II studies have proven the clinical and radiologic efficacy of Certolizumab in RA patients who had not responded to MTX treatment [28, 29]. There is proof that Certolizumab is useful in RA also as monotherapy [30].

Certolizumab is the last TNF- $\alpha$ blocker to be approved in the treatment of AS, the RAPID-ax-Spa study showing its clinical efficacy in AS, as well as in non-radiographic spondyloarthritis [31].

Certolizumab has also been approved for the treatment of PsA. Given $200 \mathrm{mg}$ subcutaneously every 2 weeks, $58 \%$ of the patients from the RAPID-PsA study had an ACR20 response after 12 weeks. The therapeutic benefit was noticed very quickly, after just 1 week 


\section{О БЗ 30 Р Ы}

[32]. Another rapid response was noticed also for the cutaneous and nails manifestations, for dactylitis, enthesitis, and physical function.

Etanercept is a fusion protein obtained from the combining two identical TNF- $\alpha$ receptor chains (p75- type II) with the Fc fragment of human $\mathrm{IgG}_{1}$. It has subcutaneous administration in a dosage of $50 \mathrm{mg}$ per week or $25 \mathrm{mg}$ twice a week. Etanercept has the ability to bind to soluble TNF- $\alpha$ molecules, preventing it from reaching and binding its specific cellular receptors. Unlike Infliximab, that also binds TNF- $\alpha$. Etanercept only neutralizes soluble, not membrane-bound, TNF- $\alpha$, leading to a milder blockade.

Etanercept has been thoroughly studied in RA, having its efficacy proven not only in association with MTX, but also as monotherapy, in patients with no response to MTX or in those who had never attempted MTX. The TEMPO study (Trial of Etanercept and Methotrexate with radiographic Patient Outcomes) showed the good results of the Etanercept ê MTX combination regarding clinical and radiologic outcomes [33]. Other studies focused on the benefits of Etanercept in both long term and early arthritis [34, 35].

In AS, Etanercept has shown its clinical use, measured by significant decreases in the BASDAI (Bath Ankylosing Spondylitis Disease Activity Index), BASFI (Bath Ankylosing Spondylitis Functional Index) and BASMI (Bath Ankylosing Spondylitis Metrology Index) scores [36]. Etanercept also diminishes vertebral inflammation (measured using MRI), has long term efficacy and works in non-radiographic spondyloarthritis, as shown by the ESTHER study [37]. The dose used in AS is similar to that for RA, $50 \mathrm{mg}$ subcutaneously once a week.

Etanercept has been studied in PsA as well. In the first study, $59 \%$ of the patients treated with Etanercept reached an ACR20 response and $23 \%$ a PASI 75 response at 24 weeks, at the same time experiencing improvements in physical function, quality of life, and radiologic progression [38]. The long-term extension of this trial showed that the therapeutic effects are maintained. The PRESTA study showed that the subcutaneous dose of $50 \mathrm{mg}$ per week has significant clinical benefits regarding ACR responses and enthesitis improvements [39].

TNF- $\alpha$ blockers have shown to be useful also for the extraarticular manifestations of spondyloarthritis. Infliximab and Adalimumab helped decrease uveitis episodes, a benefit that was not found with Etanercept [40]. Recent data suggests that Golimumab might also have a role in this regard (41). When the intestinal effects were studies, Infliximab and Adalimumab have proven to be helpful in diminishing the gastro-intestinal manifestations of both spondyloarthritis and Crohn disease, with no results using Etanercept [41].

TNF- $\alpha$ blockers are safe, the main adverse effects being $[8,42]$ :

- Higher risk for infections, especially TB;

- Higher risk for neoplasia, although data seems to show that the risk is not higher than in RA alone; lymphoma does appear more often, nevertheless;

- Increases the severity of heart failure, this being the reason why it is contraindicated in patients with stage III and IV heart failure;

- Demyelinating disease - rarely;

- Anti-DNAds antibodies and even lupus-like syndrome;

- Allergic reactions;

- Immunogenicity, with the development of antibodies against the biological agent.
TNF- $\alpha$ blockers are very efficient, but there are $35-40 \%$ of patients who do not respond to this therapy, prompting the need for medications with different modes of action.

\subsection{IL-6 blockers}

IL-6 is also a proinflammatory cytokine with an important role in the pathogenesis of RA, not only locally, but also systemically. It enhances the activation, differentiation, and proliferation of B lymphocytes, it stimulated Ig synthesis, it favors the differentiation of cytotoxic T lymphocytes and Th lymphocytes and IL-17 synthesis, leading to acute inflammation, chronic inflammation and maintaining the immune response [2]. Within the joint, IL-6 contributes to the proliferation of synoviocytes, angiogenesis, pannus formation, and bone and cartilage destruction. IL-6 also has systemic effects: it stimulates the synthesis of acute phase reactants in the liver, it causes anemia by increasing the hepatic production of hepcidin (which traps iron within macrophages), it causes fatigue by affecting the hypothalamo-pituitary axis, and it increases the cardiovascular risk by influencing lipid metabolism and through its proinflammatory effects.

Tocilizumab is a monoclonal Ab targeted against IL-6 receptor, to which it binds, blocking the cytokine and its effects. Tocilizumab is administered in IV perfusions in doses of $8 \mathrm{mg} / \mathrm{kg}$, monthly. The product has recently become available in subcutaneous administration, with the dose of $162 \mathrm{mg} /$ week. The benefits of Tocilizumab have been proven in many clinical studies, including patients with inadequate responses to MTX or other synthetic DMARDs, patients who were never treated with MTX or patients with no response to anti-TNF- $\alpha$ agents. Tocilizumab brought clinical, functional, radiologic, and quality of life improvements, not only in combination with MTX, but also as monotherapy [43-45]. Tocilizumab is considered the biological agent with the most solid evidence regarding its use as monotherapy [46].

\subsection{IL-1 blockers}

IL-1 is a proinflammatory cytokine whose actions are similar to TNF- $\alpha$. So far, there is just one IL-1 blocker approved in RA treatment, Anakinra, a human IL-1 receptor antagonist recombinant. Although Anakinra has studies proving its benefit in the treatment of RA and was the first biological agent with a different mode of action than TNF- $\alpha$ blockers, it has fallen into disuse. Its efficiency is less than that of newer biological agents and its mode of administration (daily subcutaneous injections) is inconvenient [47].

\subsection{IL-17 blockers}

At the start of 2016, the first biological agent against IL-17 was approved, Sekukinumab, a completely humanized monoclonal Ab, with two indications: AS and PsA.

The approval of Sekukinumab in AS was based on many clinical studies that showed clinical and functional benefits, expressed by improvements of at least $20 \%$ of the ASAS and ACR 20 scores after 16 and 24 weeks [48]. These results were found both in patients who had never been treated with biological agents, and in those with no response to TNF- $\alpha$ blockers. Sekukinumab is administered subcutaneously, $150 \mathrm{mg}$ in weeks $0,1,2$ and 3 , followed by a monthly maintenance dose. If the therapeutic response is not satisfying, the dosage can be increased to $300 \mathrm{mg}$ monthly. The safety profile of the drug is good, further data on this aspect remains to be obtained.

As in the case of AS, Sekukinumab was recently approved for the treatment of PsA [49]. FUTURE I and FUTURE II studies showed good therapeutic responses. Greater percentages of patients treated with Sekukinumab obtained an ACR20 response at 


\section{О БО 3 О Р Ы}

24 weeks, when compared with placebo. The safety profile was good as well, the most frequent adverse reactions being respiratory infections. The dosage is similar to that used for AS.

\subsection{IL12/23 blockers}

Ustekinumab was the first biological agent with another mode of action than TNF- $\alpha$ blockers to be approved in PsA. It is a humanized monoclonal $\mathrm{Ab}$ targeted against the p40 subunit of IL-12 and IL-23 [50]. In PSUMMIT-1 study, Ustekinumab was administered to patients who had not previously received TNF- $\alpha$ blockers. The results showed significant clinical improvements after 1 year of treatment, and the safety profile was favorable. The PSUMMIT-2 study included both patients previously treated with anti-TNF- $\alpha$ agents and some who had not taken such drugs. Both patients groups had clinical improvements (regarding articular and skin manifestations, dactylitis, enthesitis, and fatigue), as well as significant functional benefits after 24 weeks, the effects being persistent after 1 year of treatment. PSUMMIT-1 and two other studies showed that Ustekinumab could be an alternative to TNF- $\alpha$ blockers, having high efficacy and a good safety profile.

\section{Non-cytokinic therapeutic agents}

\subsection{T lymphocyte blockers}

One of the activation pathways for the T lymphocyte is the pair composed from the costimulatory molecule complex CD80/86 found on the antigen presenting cell and the CD28 receptor on the $\mathrm{T}$ lymphocytes. The binding of CD80/86 to $\mathrm{CD} 28$ activates the T lymphocyte, while the binding of CD80/86 to the CTLA-4 receptor inhibits it.

Abatacept is a completely humanized, recombinant soluble receptor, obtained through the fusion of the extracellular domain of CTLA-4 with the Fc fragment of IgG1.

This biological agent is so far approved only in the treatment of RA and it is the first representative of a new class of drugs targeting the activation of the T lymphocyte. Abatacept binds to CD80/86 on the antigen-presenting cell with a much higher affinity than CD28, thus blocking the costimulation and activation of the T lymphocyte. Through its selective action on CD80/86, Abatacept allows $\mathrm{T}$ lymphocyte activation through other pathways, thus its stimulation is not compromised. Abatacept is a biological agent that can be administered in perfusions (500-1000 $\mathrm{mg}$ in weeks $0,2,4$, then monthly), as well as subcutaneously (125 mg weekly). Randomized clinical studies have shown that Abatacept, in combination with MTX, has beneficial effects on signs and symptoms, but also on function and structural destruction in RA, in naïve MTX patients or in patients with inadequate response to MTX [51]. The long-term extensions of these studies proved the persistent therapeutic effect of Abatacept. Furthermore, Abatacept benefitted from a head-tohead trial, the AMPLE trial, being compared to Adalimumab, proving similar therapeutic effects and safety profiles [52].

\subsection{B lymphocyte blockers}

The $\mathrm{B}$ lymphocyte is an important íactorì on the stage of inflammatory rheumatic diseases pathogenesis, being involved in numerous immunopathogenic processes: it is an antigen presenting cell, contributing to the activation of the T lymphocyte, it produces proinflammatory cytokines, and it synthesizes autoantibodies [53]. CD20 is a receptor found only on the surface of B lymphocytes, not on stem cells or on plasmocytes; thus, blocking this receptor causes the depletion of peripheral B lymphocyte populations through many mechanisms: cellular cytotoxicity, complement activation and apoptosis stimulation.
Rituximab is a chimeric monoclonal Ab against the CD20 receptor found on the surface of the B lymphocyte, initially used in the treatment of non-Hodgkin lymphomas.

Clinical trials have shown than Rituximab in combination with MTX is efficient in the treatment of RA, relieving clinical symptoms and stopping the progression of structural lesions $[54,55]$. It is administered IV, the dose is $1000 \mathrm{mg}$, repeated after 2 weeks. A new cycle of 2 perfusions is administered after 6 months. The safety profile of Rituximab is good, the most frequent adverse reactions being those related to the IV perfusion and a slightly higher incidence of infections. So far, Rituximab is recommended for patients with no response to an anti-TNF- $\alpha$ agent, but in some circumstances (recent lymphoma history, latent TB with chemoprophylaxis contraindication, TB endemic region, and demyelinating disease history) it can also be used as a first-line biological agent.

Rituximab has shown favorable clinical effects in a significant percentage of systemic lupus erythematosus (SLE), irrespective of the presence of nephropathy, in many studies and registries. Two randomized trials (EXPLORER and LUNAR) failed to prove its superiority over the conventional therapy [56], so Rituximab has not yet been approved in the treatment of LES.

In 2011, the FDA approved the use of Rituximab in granulomatosis with polyangiitis and in microscopic polyangiitis, thus becoming the first biological agent with these indications [57]. The RAVE study (Rituximab in ANCA-Associated Vasculitis) was a multicentric, randomized, double-blind, non-inferiority study that evaluated the efficacy and safety of Rituximab in comparison to the standard therapy in these ANCA-Associated vasculitis. The main objective was obtaining remission after 6 months, in the absence of steroids [58]. This objective was reached by $64 \%$ of patients treated with Rituximab and by $53 \%$ of those on the standard therapy, thus is was proven to be non-inferior. There were no differences regarding side effects between the two patients groups. Furthermore, patients treated with Rituximab obtained better results after a relapse than those on Cyclophosphamide. The longterm data showed that in the severe cases of ANCA-Associated vasculitis, a single weekly dose of $375 \mathrm{mg} / \mathrm{m}^{2}$ of Rituximab, for 4 weeks, associated with corticotherapy, was not inferior to the conventional treatment of steroids and Cyclophosphamide, followed by a maintenance treatment with Azathioprine for remission after 18 months [59].

In 2011, FDA approved the first biologic agent in SLE, Belimumab [60]. This is a monoclonal anti-BLyS (B-lymphocyte stimulator) or BAFF (B-cell activating factor) $\mathrm{Ab}$, a molecule with an essential contribution to the proliferation, activation and survival of B lymphocytes. This molecule can be secreted by more cell types, such as: macrophages, monocytes, medullary stromal cells, and synoviocytes [61]. In SLE, BLyS synthesis is increased, thus administering a monoclonal anti-BLyS $\mathrm{Ab}$ can bring therapeutic effects.

The efficacy and safety of Belimumab have been studied in many clinical trials. The BLISS52 and BLISS76 studies showed that Belimumab, administered IV in a dose of $10 \mathrm{mg} / \mathrm{kg}$ once a month, added to the standard treatment, proved better therapeutic responses than the standard treatment alone, evaluated through SRI (SLE Responder Index) after 1 year of treatment $[62,63]$. Using Belimumab led to improvements in cutaneous and articular signs and symptoms, as well as in serology. Because these studies excluded patients with severe nephropathy, Belimumab is so far recommended only in SLE without nephropathy. Trials to evaluate its efficacy in patients with 


\section{О БЗ 3 О Р Ы}

nephropathy are ongoing. Furthermore, Belimumab was proven to be well tolerated, but further long-term data is required to better understand its safety profile.

\section{Summary of biological treatments available}

In summary, immune-mediated inflammatory rheumatic diseases that benefit from treatment options with biological agents are:

- RA:

- anti-TNF-agents: Infliximab, Adalimumab, Certolizumab, Golimumab, Etanercept

- anti-IL-6-agents: Tocilizumab

- anti-IL-1-agents: Anakinra

- anti-B lymphocyte-agents: Rituximab

- anti-costimulation molecules agents: Abatacept

- AS:

- anti-TNF-agents: Infliximab, Adalimumab, Certolizumab, Golimumab, Etanercept

- anti-IL-17-agents: Sekukinumab

- PsA:

- anti-TNF-agents: Infliximab, Adalimumab, Certolizumab, Golimumab, Etanercept

- anti-IL-17-agents: Sekukinumab

- anti-IL-12/23-agents: Ustekinumab

- SLE:

- anti-BLyS-agents: Belimumab

- some ANCA-associated vasculitides:

- anti-B lymphocyte-agents: Rituximab

\section{Clinical practice in Romania}

In emerging market regions such as Central and Eastern Europe, disparity due to economic and social factors provides challenges to achieving optimal monitoring and treatment of immunemediated inflammatory diseases.

Several countries of this region, including Romania, have adapted «treat to target» guidelines that are in line with the current EULAR Recommendations [64]. Following consensus guidelines for early, aggressive treatment to target with biologic agents will be critical for narrowing the treatment gap in this region [65].

Consequently, in Romania several opportunities for tightening treatment differences in these diseases were followed: implementing focused patient education initiatives along with physician educational programs and healthcare provider education to increase overall awareness of the importance of early diagnosis and treatment, providing regulators and healthcare payers with this information along with health-economic data in order to convince these authorities to maximize early treatment with biologics.

Another important step was the development of a national registry, «The Romanian Registry of Rheumatic Diseases» (RRBR). This is an electronic application that includes data of all RA, AS and PsA patients treated with biologics in Romania. In this Registry, initiated in February 2013, multiple variables are collected: demographics, diseases history, therapies, diseases activity, adverse events, lab results, PRO, and others, in order to provide data for these patients in our country [66]. The application belongs to the Association «Romanian Registry of Rheumatic Diseases», a nonprofit organization initiated by the Romanian Society of Rheumatology. Data is entered in the Registry by the rheumatologist in charge of the patientis care, after the patient signs an informed consent form.

Including patients in this registry is mandatory, in order to obtain reimbursement for biologics. At the beginning of 2017, almost 10000 patients (more than 60\% being RA patients) were included in the Registry [67].

In Romania, the cost of biological treatment for RA, AS and PsA is fully reimbursed by the National Insurance House (NIH) for eight biologic agents [68]:

- five TNF- $\alpha$ blockers for RA, AS and PsA (Infliximab, including biosimilars, Etanercept, Adalimumab, Golimumab, Certolizumab)

- for RA, there is also reimbursement for three biologic agents with a different mode of action: Rituximab, Tocilizumab and Abatacept.

At the moment, no biological treatment for other immunemediated inflammatory rheumatic diseases (like SLE or vasculitis) is reimbursed.

The NIH has established the criteria which must be fulfilled by the patients in order to be eligible for biological treatment $[69,70]$ :

\subsection{Criteria for biological treatment in $R A$}

For RA, the patient must have an active disease, despite treatment with at least two synthetic DMARDs (mainly methotrexate, leflunomide, or sulfasalazine; methotrexate is a mandatory option, if there is no proven contraindication) at maximal doses, for at least 12 weeks each, and have no contraindications for biological therapy. An active disease is defined as a Disease Activity Score with 28 joints (DAS28) over 5.1, including a total of at least five painful and swollen joints, and an increased acute phase reactant: erythrocyte sedimentation rate $(\mathrm{ESR})>28 \mathrm{~mm} /$ hour or $\mathrm{C}$ reactive protein (CRP), quantitative assay, over 3 times the upper limit.

Outcome assessments are conducted after 6 months of treatment, using DAS28, Simplified Disease Activity Index (SDAI), and Clinical Disease Activity Index (CDAI) as outcome measures. A patient is considered to be a responder if DAS28 improves with more than 1.2 or achives a value $<3.2$ ) and responders are approved for another 6 months. Treatment outcomes are re-assessed every 6 months, thereafter. If a patient is found to be a non-responder, switching to another biologic agent is recommended. Importantly, a shared decision between patient and physician determines the prescribed switch.

\subsection{Criteria for biological treatment in $A S$}

AS patients must have severe, active disease define by: BASDAI repeatedly over 6, Ankylosing Spondylitis Disease Activity Score - ASDAS - over 2.5, and an increased acute phase reactant: ESR $>28 \mathrm{~mm} /$ hour or CRP, quantitative assay, over 3 times the upper limit), not controlled with traditional therapies at maximally tolerated doses (at least two nonsteroidal anti-inflammatory drugs NSAIDs - for 6 weeks each in patients with axial disease). For patients with peripheral disease, sulfasalazine for at least 4 months at maximal doses is also mandatory, as well as local injections of glucocorticoids for active peripheral arthritis or enthesitis. Coxofemoral joint involvement and extraarticular manifestations are factors which allow the initiation of biological therapy earlier, with lower disease activity scores (BASDAI $>4$, ASDAS $>2.1$ ).

\subsection{Criteria for biological treatment in PSA}

To be considered for biological therapy, the disease activity must be high (Disease Activity in Psoriatic Arthritis - DAPSA score over 28), with at least 5 tender and swollen joints, and CRP, quantitative assay, over 3 times the upper limit. Traditional treatments, administered according to the guidelines, in maximally tolerated doses, must be proven inefficient for controlling the disease: at least two synthetic DMARDs for 12 weeks each (methotrexate is a mandatory option, if there is no proven contraindication), at least 


\section{О БЗ О Р Ы}

two NSAIDs for 6 weeks each for axial arthritis, enthesitis, or dactylitis, or local injections of glucocorticoids for enthesitis or dactylitis. If there are negative prognostic factors associated with PsA, a treatment with one synthetic DMARD for 12 weeks is enough for the switch to biological agents.

\section{Conclusions}

There are several emerging market regions ê including Romania ê that have committed to these types of initiatives, with the goal of decreasing the burden of immune-mediated inflammatory diseases.

A second important step in decreasing treatment disparities is for rheumatologists to adapt their strategies to fit the ACR/EULAR guidelines for treating to target [71]. Romania has been included in the «treat to target» dialogue, and many rheumatologists in this country have shifted their approach on the management of these diseases to fit the guidelines. However, there is much to be done for the purposes of reimbursement of all biological agents and extension of the reimbursement of this treatment to other inflammatory rheumatic diseases.

As more nations in Central and Eastern Europe adapt these approaches, patients with immune-mediated inflammatory diseases will be able to achieve the best treatment outcomes.

So far, the use of biological agents in rheumatology is an extremely dynamic process. The range of these therapeutic instruments is permanently widened by the addition of new drugs with new indications. In diseases like RA, AS or PsA there are over 15 years of experience with many such agents from different classes, and their numbers keep on increasing. For other diseases, like SLE and vasculitis, this journey is just beginning, the experience in the use of biological agents being way less. There are other rheumatic diseases, like scleroderma, nonspecific inflammatory myopathies, Sjögren syndrome, or other vasculitis, for which no biological agents have been approved so far, but many studies are still underway concerning them.

\section{R E}

1. Balanescu A. Progrese in tratamentul biologic al bolilor reumatice. In: Gherasim L. Actualitati in medicina interna. Bucuresti: Editura Medicala, 2015;28:739-764.

2. Choy E, G. P. Cytokine pathways and joint inflammation in rheumatoid arthritis. $N$ Engl J Med 2001;344(12):907-916.

3. Dinarelo C, L. M. Proinflammatory and anti-inflammatory cytokines in rheumatoid arthritis - a primer for clinicians. Thoussand Oaks C, editor: Amgen Inc; 2000.

4. Lam J, Abu-Amer Y, Nelson C, Fremont D, Ross F, S. T. Tumour necrosis factor superfamily cytokines and the pathogenesis of inflammatory osteolysis. Ann Rheum Dis 2002;61(suppl II):ii82-83. 5. Maini R, St. Clair E, Breedveld F, Furst D, Kalden J, M. W. Infliximab (chimeric antitumour necrosis factor alpha monoclonal antibody) versus placebo in rheumatoid arthritis patients receiving concomitant methotrexate: a randomised phase III trial. Lancet 1999;354:1932-1939.

6. Maini R, Breedveld F, Kalden J, Smolen J, Furst D, M. W. Sustained improvement over two years in physical function, structural damage, and signs and symotoms among patients with rheumatoid arthritis treated with infliximab and methotrexate. Arthritis Rheum 2004;50:1051-1065.

7. Smolen J.S, Han C, Bala M, Maini R.N, Kalden J.R, van der Heijde D, et al. Evidence of radiographic benefit of treatment with infliximab plus methotrexate in rheumatoid arthritis patients who had no clinical improvement: a detailed subanalysis of data from the anti-tumor necrosis factor trial in rheumatoid arthritis with concomitant therapy study Arthritis Rheum. 2005;52(4):1020-1030. 8. Nam JL, Ramiro S, Gaujoux-Viala C, Takase K, Leon-Garcia M, Emery P, et al. Efficacy of biological disease-modifying antirheumatic drugs: a systematic literature review informing the 2013 update of the EULAR recommendations for the manage- ment of rheumatoid arthritis. Ann Rheum Dis. 2014; Online First, published on January 7 , 2014 as 10.1136/annrheumdis-2013-204577. 9. van der Heijde D, Dijkmans B, P. G. Efficacy and safety of infliximab in patients with ankylosing spondylitis: results of a randomized, placebo-controlled trial (ASSERT). Arthritis Rheum 2005;52:582-591.

10. Braun J, Landewe R, KG. H. Major reduction in spinal inflammation in patients with ankylosing spondylitis after treatment with infliximab: results of a multicentre, randomized, double-blind, placebo-controlled magnetic resonance imaging study. Arthritis Rheum. 2006;54:1646-1652.

11. Goh L, S. A. Update on biologic therapies in ankylosing spondylitis: a literature review. International Journal of Rheumatic Diseases. 2012;15:445-454.

12. Sieper J, Lenaerts J, Wollenhaupt J, Rudwaleit M, Mazurov V, L. M. Efficacy and safety of infliximab plus naproxen versus naproxen alone in patients with early, active axial spondyloarthritis: results from the double-blind, placebo-controlled INFAST study. Ann Rheum Dis 2014;73:101-107. 13. Kavanaugh A, Antoni CE, Gladman D, Wassenberg S, Zhou B, Beutler A, et al. The Infliximab Multinational Psoriatic Arthritis Controlled Trial (IMPACT): results of radiographic analyses after 1 year. Ann Rheum Dis. 2006;65(8):1038-1043.

14. Weinblatt M, Keystone E, Furst D, Moreland L, M. W. Adalimumab, a fully human anti-tumor necrosis factor alpha monoclonal antibody, for the treatment of rheumatoid arthritis in patients taking concomitent methotrexate: the ARMADA study. Arthritis Rheum 2003;48:35-45. 15. van de Putte L, Atkins C, M. M. Efficacy and safety of adalimumab as monotherapy in patients with rheumatoid arthritis for whom previous disease modifying antirheumatic dryg treatment failed. Ann Rheum Dis. 2004;63:508-516.
16. Keystone E, Kavanaugh A, J. S. Radiographic, clinical and functional outcomes of treatment with adalimumab (a human anti-tumor necrosis alpha antibody) in patients with active rheumatoid arthritis receiving concomitent methotrexate therapy: a randomised, placebo-controlled 52 week trial. Arthritis Rheum 2004;50:1400-1411. 17. Weinblatt M, Keystone E, Furst D, Kavanaugh A, Chartash E, O. S. Long term efficacy and safety of adalimumab plus methotrexate in patients with rheumatoid arthritis: ARMADA 4 year extended study. Ann Intern Med 2006;65:753-759.

18. Breedveld F, Weisman M, Kavanaugh A, S. C. The PREMIER Study: a multicentric, randomized, double-blind clinical trial of combination therapy with adalimumab plus methotrexate versus methotrexate alone or adalimumab alone in patients with early, aggressive rheumatoid arthritis who had not had previous methotrexate treatment. Arthritis Rheum 2006;54:26-37.

19. Van der Heijde D, Kivitz A, MH. S. Efficacy and safety of adalimumab in patients with ankylosing spondylitis: results of a multicenter, randomized, doubleblind, placebocontrolled trial. Arthritis Rheum 2006;54: 2136-2146.

20. Rudwaleit M, Olivieri I, KA. B.

Adalimumab is effective and well tolerated in treating patients with ankylosing spondylitis who have advanced spinal fusion.

Rheumatology (Oxford). 2009;48:551-557. 21. Sieper J, van der Heijde D, Dougados M, Mease P, Maksymowych W, M. B. Efficacy and safety of adalimumab in patients with non-radiographic axial spondyloarthritis: results of a randomised placebo-controlled trial (ABILITY-1). Ann Rheum Dis 2013;72: 815-822.

22. Keystone EC, Genovese MC, L. K. Golimumab, a human antibody to TNF- $\alpha$ given by monthly subcutaneous injections, in active rheumatoid arthritis despite 
methotrexate:the GO-FORWARD study. Ann Rheum Dis. 2009;68:789-796.

23. Kay J, M. R. Golimumab: A novel human anti-TNF- $\alpha$ monoclonal antibody for the treatment of rheumatoid arthritis, ankylosing spondylitis, and psoriatic arthritis. Arthritis Rheum. 2008;58 (4):964-975.

24. Inman RD, Davis JC Jr, D. vdH. Efficacy and safety of golimumab in patients with ankylosing spondylitis: results of a randomized, double-blind, placebo-controlled, phase III trial. Arthritis Rheum 2008;58:3402-3412. 25. Kavanaugh A, van der Heijde D, McInnes IB, Mease P, Krueger GG, Gladman DD, et al. Golimumab in psoriatic arthritis: one-year clinical efficacy, radiographic, and safety results from a phase III, randomized, placebo-controlled trial. Arthritis Rheum. 2012;64(8):2504-2517. 26. Kavanaugh A, McInnes IB, Mease P, Krueger GG, Gladman D, van der Heijde D, et al. Clinical efficacy, radiographic and safety findings through 5 years of subcutaneous golimumab treatment in patients with active psoriatic arthritis: results from a long-term extension of a randomised, placebo-controlled trial (the GO-REVEAL study). Ann Rheum Dis. 2014;[Epub ahead of print]. 27. McDonnell T, Ioannou Y, A. R. PEGylated drugs in rheumatology-why develop them and do they work? Rheumatology (Oxford). 2014;53(3):391-396. 28. Keystone E, van den Heijde D, D M. Certolizumab Pegol Plus Methotrexate Is Significantly More Effective Than Placebo Plus Methotrexate In Active Rheumatoid Arthritis. Arthritis \& Rheum. 2008;58;11: 3319-3329.

29. Smolen J, Landewe R, P. M. Efficacy and safety of certolizumab pegol plus methotrexate in active rheumatoid arthritis: the RAPID 2 study. A randomised controlled trial. Ann Rheum Dis. 2009;68:797-804.

30. Fleischmann R, Vencovsky J, RF. vV. Efficacy and safety of certolizumab pegol monotherapy every 4 weeks in patients with rheumatoid arthritis failing previous diseasemodifying antirheumatic therapy: the FAST4WARD study. Ann Rheum Dis. 2009;68:805-811.

31. Landewe R, J B, Deodhar A, Dougados M, Maksymowych W, P. M. Efficacy of certolizumab pegol on signs and symptoms of axial spondyloarthritis including ankylosing spondylitis: 24-week results of a double-blind randomised placebo-controlled phase 3 study. Ann Rheum Dis 2014;73:39-47. 32. Mease PJ, Fleischmann R, Deodhar AA, Wollenhaupt J, Khraishi M, Kielar D, et al. Effect of certolizumab pegol on signs and symptoms in patients with psoriatic arthritis: 24 week results of a Phase 3 double-blind randomised placebo-controlled study (RAPID-PsA). Ann Rheum Dis. 2014;73(1): 48-55.

33. Klareskog L, van der Heijde D, J. dJ. Therapeutic effect of the combination of etanercept and methotrexate compared with each treatment alone in patients with rheumatoid arthritis: double-blind randomized trial. Lancet 2004;363:675-681.

34. Emery P, Breedveld F, van der Heijde D, Ferraccioli G, Dougados M, Robertson D, et al. Two-Year Clinical and Radiographic Results With Combination EtanerceptMethotrexate Therapy Versus Monotherapy in Early Rheumatoid Arthritis. Arthritis \& Rheum. 2010;62:674-682.

35. Canete J, J. P. Biologic Therapy in Rheumatoid Arthritis. Current Topics in Medicinal Chemistry. 2013;13:752-759. 36. Dougados M, Braun J, S. S. Efficacy of etanercept on rheumatic signs and pulmonary function tests in advanced ankylosing spondylitis: results of a randomised doubleblind placebo-controlled study (SPINE). Ann Rheum Dis 2011;70(799-804).

37. Song I, Weib A, Hermann K, Haibel H, Althoff C, D. P. Similar response rates in patients with ankylosing spondylitis and nonradiographic axial spondyloarthritis after 1 year of treatment with etanercept: results from the ESTHER trial. Ann Rheum Dis 2013;7:823-825.

38. Mease PJ, Goffe BS, Metz J, VanderStoep A, Finck B, DJ. B. Etanercept in the treatment of psoriatic arthritis and psoriasis: a randomised trial. Lancet. 2000;29;356(9227): 385-390.

39. Sterry W, Ortonne JP, B. K. Comparison of two etanercept regimens for treatment of psoriasis and psoriatic arthritis: PRESTA randomized double blind multicentre trial. $B M J$ 2010;340:C147.

40. Bruner V, Atteno M, Spano A, Scarpa R, R. P. Biological therapies for spondyloarthritis. Ther Adv Musculoskel Dis. 2014; 6(3) $92-101$.

41. Miserocchi E, Modorati G, Pontikaki I, Meroni P, V. G. Long-term treatment with golimumab for severe uveitis. Ocul Immunol Inflamm. 2013:(Epub ahead of print).

42. Ramiro S, Gaujoux-Viala C, Nam J, Smolen J, Buch M, Gossec L, et al. Safety of synthetic and biological DMARDs: a systematic literature review informing the 2013 update of the EULAR recommendations for management of rheumatoid arthritis. Ann Rheum Dis 2014;73:529-535.

43. Rueda Gotor J, R. BA. Tocilizumab in rheumatoid arthritis. Reumatol Clin. 2011;6S3: S29-32.

44. Jones G, Sebba A, Gu J, Lowenstein MB, Calvo A, Gomez-Reino JJ, et al. Comparison of tocilizumab monotherapy versus methotrexate monotherapy in patients with moderate to severe rheumatoid arthritis: the AMBITION study. Ann Rheum Dis. 2010; 69(1):88-96.

45. Kaufmann J, Feist E, Roske AE, WA. S. Monotherapy with tocilizumab or TNF-alpha inhibitors in patients with rheumatoid arthritis: efficacy, treatment satisfaction, and persistence in routine clinical practice. Clin
Rheumatol. 2013; May 24.

[Epub ahead of print].

46. Smolen J, Landewe R, F B. EULAR recommendations for the management of rheumatoid arthritis with synthetic and biological disease modifying antirheumatic drugs: 2013 update. Ann Rheum Dis 2014; 73:492-509.

47. Meier F, Frerix M, Hermann M, U. Ml-L. Current immunotherapy in rheumatoid arthritis. Immunotherapy. 2013;5(9):955-974. 48. Baeten D, Sieper J, Braun J, et al. Secukinumab, interleukin-17A inhibition in ankylosing spondylitis. $N$ Engl J Med. 2015; 373:2534-48.

49. Mease PJ, McInnes IB, Kirkham B, et al. Secukinumab inhibition of interleukin-17A in patients with psoriatic arthritis. $N$ Engl J Med. 2015; 373(14):1329-39.

50. Ritchlin C, Rahman P, Kavanaugh A, McInnes IB, Puig L, Li S, et al. Efficacy and safety of the anti-IL-12/23 p40 monoclonal antibody, ustekinumab, in patients with active psoriatic arthritis despite conventional nonbiological and biological anti-tumour necrosis factor therapy: 6-month and 1-year results of the phase 3, multicentre, double-blind, placebo-controlled, randomised PSUMMIT 2 trial. Ann Rheum Dis. 2014;73(6):990-999. 51. Caporali R, Bugatti S, Cavagna L, Antivalle M, P. S-P. Modulating the co-stimulatory signal for $\mathrm{T}$ cell activation in rheumatoid arthritis: Could it be the first step of the treatment? Autoimmunity Reviews 2014; 13:49-53.

52. Weinblatt ME, Schiff M, R. V. Headto-head comparison of subcutaneous abatacept versus adalimumab for rheumatoid arthritis: findings of a Phase IIIb, multinational, prospective, randomized study. Arthritis Rheum. 2013;65(1):28-38.

53. Edwards J, G. C. Sustained improvement in rheumatoid arthritis following a protocol designed to deplete B lymphocyte.

Rheumatology (Oxford) 2001;40:205-211.

54. Edwards J, Szczepanski A, P. E. Efficacy of B-cell-targeted therapy with rituximab in patients with rheumatoid arthritis. $N$ Engl $J$ Med 2004;350:2572-2581.

55. Emery P, Fleischmann R, FilipowiczSosnowska A, Schechtman J, A. K. The efficacy and safety of rituximab in patients with active rheumatoid arthritis despite methotrexate treatment: results of a phase IIb double-blind, placebo-controlled, doseranging trial (DANCER). Arthritis Rheum 2006;54:1390-1400.

56. Ding HJ, C. G. New biologic therapy for systemic lupus erythematosus. Current Opinion in Pharmacology 2013;13:405-412.

57. FDA. http://www.fda.gov/NewsEvents/ Newsroom/PressAnnouncements/ucm25194 6.htm. 2011.

58. Stone JH, Merkel PA, R. S. Rituximab versus cyclophosphamide for ANCA-associated vasculitis. $N$ Engl J Med. 2010;363: 221-232. 


\section{О Б 30 Р Ы}

59. Specks U, Merkel PA, Seo P, Spiera R, Langford CA, Hoffman GS, et al. Efficacy of remission-induction regimens for ANCAassociated vasculitis. $N$ Engl J Med. 2013; 369(5):417-427.

60. FDA. "FDA approves Benlysta to treat lupus" (Press release). U.S. Food and Drug Administration (FDA). March 9, 2011. 2011. 61. Schneider P. The role of APRIL and BAFF in lymphocyte activation. Curr Opin Immunol. 2005; 17 (3):282-289.

62. Navarra SV, Guzma RM, Gallacher AE, Hall S, Levy RA, Jimenez RE, et al. Efficacy and safety of belimumab in patients with active systemic lupus erythematosus: a randomised, placebo-controlled, phase 3 trial. Lancet 2011;377:721-731.

63. Furie R, Petri M, Zamani O, Cervera R, Wallace DJ, Tegzova D, et al. A phase III, randomized, placebo-controlled study of belimumab, a monoclonal antibody that inhibits
B lymphocyte stimulator, in patients with systemic lupus erythematosus. Arthritis Rheum 2011;63:3918-3930.

64. Smolen JS, et al. EULAR recommendations for the management of rheumatoid arthritis with synthetic and biological diseasemodifying antirheumatic drugs: 2016 update. Ann Rheum Dis 2017;0:1-18. doi:10.1136/ annrheumdis-2016-210715

65. Balanescu A, Wiland P. Maximizing early treatment with biologics in patients with rheumatoid arthritis: the ultimate breakthrough in joints preservation. Rheumatol Int. 2013 Jun;33(6):1379-86.

66. Codreanu C, Mogosanu C, Ionescu R, Ancuta I, Opris, D. Biologic Therapy In Rheumatoid Arthritis: Results From The Romanian Registry Of Rheumatic Diseases One Year After Initiation. Farmacia. 2014; 62(6):1089-96.

67. Ionescu R. Oral communication, «The
Romanian Registry Of Rheumatic Diseases» Annual Meeting, Bucharest, 2 March 2017. 68. Ordinul MSP/ CNAS nr. 1301/ 500/ 2008 pentru aprobarea protocoalelor terapeutice privind prescrierea medicamentelor. Retrieved from http://www.cnas.ro/casnt/ post/ordinul-msp-cnas-nr-1301-500-2008pentru-aprobarea-protocoalelor-terapeuticeprivind-prescrierea-med.html. 69. Ordinul nr 141/2017. Retrieved from http://amfms.ro/ordinul-nr-1412017/. 70. Retrieved from http://www.ms.ro/wpcontent/uploads/2017/02/Ordin-protocoale2017Anexa.pdf.

71. Smolen JS, Breedveld FC, Burmester GR, et al. Treating rheumatoid arthritis to target: 2014 update of the recommendations of an international task force Ann Rheum Dis 2016;75:3-15.

Поступила 2.08.2017

Исследование не имело спонсорской поддержки. Авторы несут полную ответственность за предоставление окончательной версии рукописи в печать. Все авторы принимали участие в разработке концепции статьи и написании рукописи. Окончательная версия рукописи была одобрена всеми авторами. 